\title{
Simulation of a Solar Cell considering Single-Diode Equivalent Circuit Model
}

\author{
E.M.G. Rodrigues ${ }^{1}$, R. Melício ${ }^{1,2}$, V.M.F. Mendes ${ }^{3}$ and J.P.S. Catalão ${ }^{1,2}$ \\ ${ }^{1}$ University of Beira Interior \\ R. Fonte do Lameiro, 6200-001 Covilhã (Portugal) \\ Phone: +351 275329 914, Fax: +351 275329972 \\ e-mail: eduardorodrigues@netc.pt, ruimelicio@gmail.com \\ ${ }^{2}$ Center for Innovation in Electrical and Energy Engineering, Instituto Superior Técnico \\ Av. Rovisco Pais 1, 1049-001 Lisbon (Portugal) \\ Phone: +351218417 000, Fax: +351218 499242 \\ e-mail: catalao@ubi.pt \\ ${ }^{3}$ Instituto Superior de Engenharia de Lisboa \\ R. Conselheiro Emídio Navarro, 1950-062 Lisbon (Portugal) \\ Phone: +351218 317 000, Fax: +351218 317001 \\ e-mail: vfmendes@isel.pt
}

\begin{abstract}
This paper focuses on single-diode photovoltaic cell models. Comprehensive simulation studies are carried out in order to adequately assess temperature dependence, solar radiation change, diode ideality factor and series resistance influence. A comparison between an ideal model single-diode solar cell and a model of single-diode solar cell with a series resistance is also presented. Finally, conclusions are duly drawn.
\end{abstract}

\section{Key words}

Photovoltaic energy, solar cells, modelling, simulation.

\section{Introduction}

In recent years, significant photovoltaic (PV) deployment has occurred, particularly in Germany, Spain and Japan [1]. Also, PV energy is expected to become an important player in the coming years in Portugal, since it is one of the European countries with the highest levels of solar radiation. Sunshine in mainland Portugal varies between 1800 and 3100 hours per year, so the country has a huge potential for solar energy exploitation.

At the present the tenth largest PV power plant in the world is in Moura, Portugal, with an installed capacity of $46 \mathrm{MW}$. The aim is to reach $1500 \mathrm{MW}$ of installed capacity by 2020 , according to the Portuguese National Strategy ENE 2020, multiplying tenfold the existing capacity [2].

A PV system directly converts sunlight into electricity. The main device of a PV system is a solar cell. Cells may be grouped to form panels or arrays. Powerelectronic converters are usually required to process the electricity from the PV device. These converters may be used to regulate the voltage and current at the load, to control the power flow in grid-connected systems, and for the maximum power point tracking (MPPT) of the device [3].
The solar cell is basically a semiconductor diode exposed to light. Solar cells are made of several types of semiconductors using different manufacturing processes [4].

The electrical energy produced by a solar cell at any time instant depends on its intrinsic properties and the incoming solar radiation [5].

The solar radiation is composed of photons of different energies, and some are absorbed at the $p-n$ junction. Photons with energies lower than the bandgap of the solar cell are useless and generate no voltage or electric current. Photons with energy superior to the bandgap generate electricity, but only the energy corresponding to the bandgap is used. The remainder of energy is dissipated as heat in the body of the solar cell [6].

A single-diode PV cell model is considered in this paper, including the effect of the series resistance. The paper uses the equivalent circuit of a solar cell with its parameters as a tool to simulate in order to consider the irradiance and temperature change, the I-V characteristics of PV cell.

\section{Modelling}

\section{A. Ideal Solar Cell}

As mentioned previously, the solar cells are semiconductor with a $p-n$ junction fabricated in a thin wafer or layer of semiconductors. When exposed to light a photo current proportional to the solar radiation is generated, if the photon energy is greater than the band gap. In the dark, the I-V characteristics of a solar cell have an exponential characteristic similar to that of a diode [7].

In order to maximize the extracted output power from a PV power plant with the help of MPPT control, the understanding and modelling of PV cell is necessary [8]. 
The ideal equivalent circuit of a solar cell is a current source in parallel with a single-diode. The configuration of the simulated ideal solar cell with single-diode is shown in Figure 1.

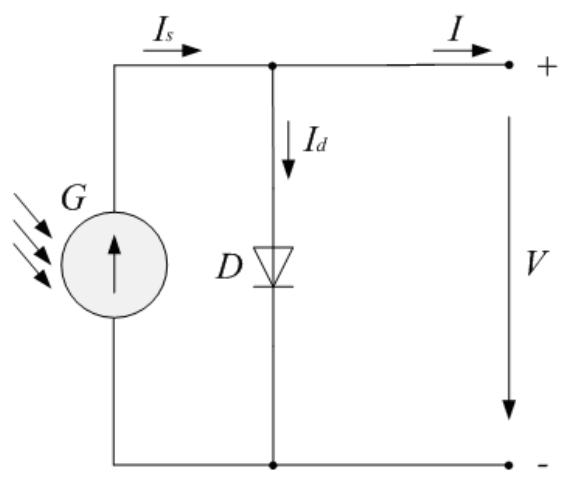

Fig. 1. Ideal solar cell with single-diode.

In Figure 1, $G$ is the solar radiance, $I_{s}$ is the photo generated current, $I_{d}$ is the diode current, $I$ is the output current, and $V$ is the terminal voltage.

The I-V characteristics of the ideal solar cell with singlediode are given by:

$I=I_{s}-I_{0}\left(e^{\frac{q V}{m k T}}-1\right)$

where $I_{0}$ is the diode reverse bias saturation current, $q$ is the electron charge, $m$ is the diode ideality factor, $k$ is the Boltzman's constant, and $T$ is the cell temperature.

A solar cell can at least be characterised by the short circuit current $I_{s c}$, the open circuit voltage $V_{o c}$, and the diode ideality factor $m$.

For the same irradiance and $p-n$ junction temperature conditions, the short circuit current $I_{s c}$ it is the greatest value of the current generated by the cell. The short circuit current $I_{s c}$ is given by:

$I_{s c}=I=I_{s}$ for $\quad V=0$

For the same irradiance and $p-n$ junction temperature conditions, the open circuit voltage $V_{o c}$ is the greatest value of the voltage at the cell terminals [7]. The open circuit voltage $V_{o c}$ is given by:

$V=V_{o c}=\frac{m k T}{q} \ln \left(1+\frac{I_{s c}}{I_{0}}\right)$ for $\quad I=0$

The output power is given by:

$P=V\left[I_{s c}-I_{0}\left(e^{\frac{q V}{m k T}}-1\right)\right]$

\section{B. Solar Cell with Series Resistance}

More accuracy can be introduced to the model by adding a series resistance. The configuration of the simulated solar cell with single-diode and series resistance is shown in Figure 2.

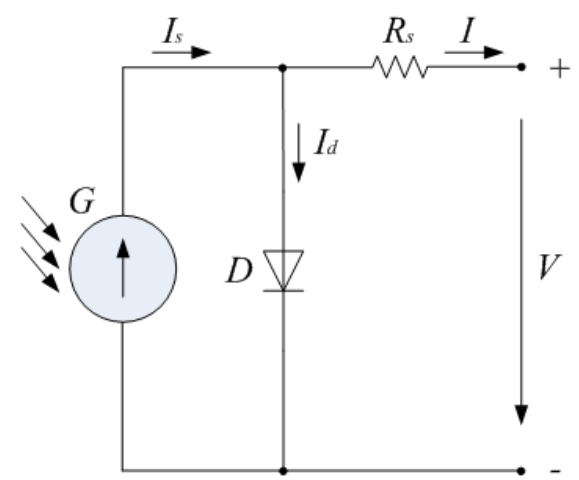

Fig. 2. Solar cell with single-diode and series resistance.

The I-V characteristics of the solar cell with single-diode and series resistance are given by:

$I=I_{S}-I_{0}\left[e^{\frac{q\left(V+R_{s} I\right)}{m k T}}-1\right]$

For the same irradiance and $p-n$ junction temperature conditions, the inclusion of a series resistance in the model implies the use of a recurrent equation to determine the output current in function of the terminal voltage. A simple iterative technique initially tried only converged for positive currents. The Newton-Raphson method converges more rapidly and for both positive and negative currents [7].

The short circuit current $I_{s c}$ is given by:

$I_{s c}=I=I_{s}-I_{0}\left[e^{\frac{q\left(R_{s} I_{s c}\right)}{m k T}}-1\right]$ for $V=0$

Normally the series resistance is small and negligible in computing (6). Hence, it is used (2) as a good approximation of (6). The open circuit voltage $V_{o c}$ is given by:

$V=V_{o c}=\frac{m k T}{q} \ln \left(1+\frac{I_{s c}}{I_{0}}\right)$ for $\quad I=0$

The output power is given by:

$P=V\left[I_{s c}-I_{0}\left(e^{\frac{q\left(V+R_{s} I\right)}{m k T}}-1\right)\right]$

The diode saturation current at the operating-cell temperature is given by: 
$I_{0}=I_{0}^{*}\left(\frac{T_{c}}{T^{*}}\right)^{3} e^{\frac{\varepsilon q}{m k}\left(\frac{1}{T^{*}}-\frac{1}{T_{c}}\right)}$

where $I_{0}^{*}$ is the diode saturation current at reference condition, $T_{c}$ is the $p$ - $n$ junction cell temperature, $T^{*}$ is the cell $p-n$ junction temperature at reference condition, and $\varepsilon$ is the bandgap.

\section{Simulation Results}

The mathematical models for the ideal solar cell and the solar cell with series resistance were implemented in Matlab/Simulink.

The I-V characteristics for various conditions of solar radiation and $m=1.66$, considering the ideal solar cell, are shown in Figure 3.

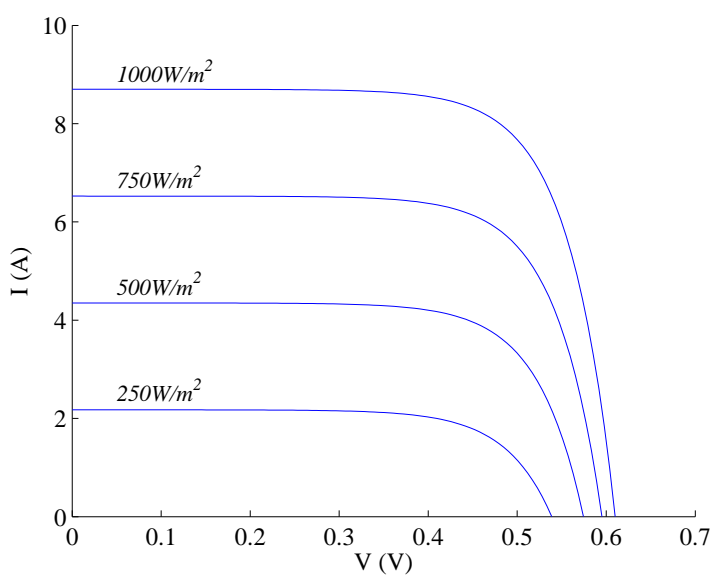

Fig. 3. I-V characteristics for various conditions of solar radiation.

The I-V characteristics for a diode ideality factor variation between 1 and 2, considering the ideal solar cell, are shown in Figure 4.

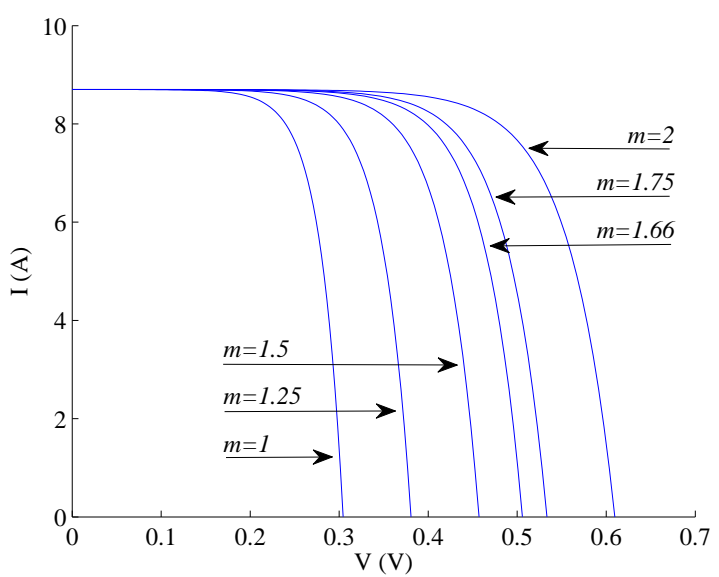

Fig. 4. I-V characteristics for a diode ideality variation between 1 and 2 .

The I-V characteristics for a temperature variation between 0 and $75^{\circ} \mathrm{C}$ and $m=1.66$, considering the ideal solar cell, are shown in Figure 5.

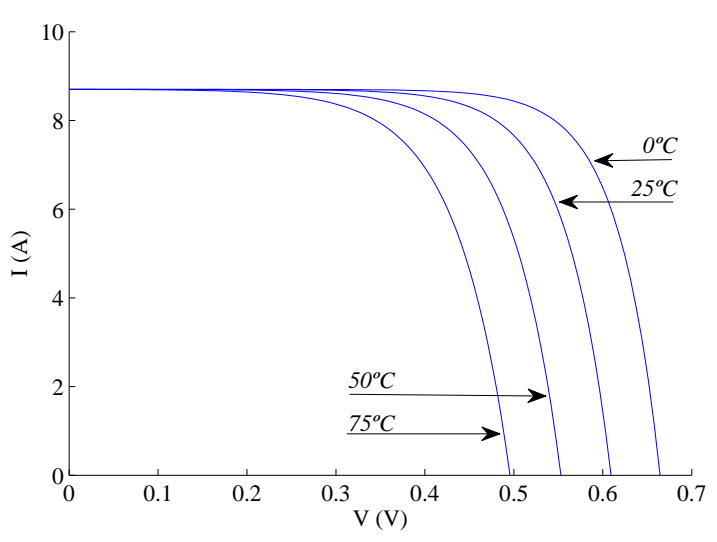

Fig. 5. I-V characteristics for the temperature variation between 0 and $75^{\circ} \mathrm{C}$.

The P-V characteristics for the temperature variation between 0 and $75^{\circ} \mathrm{C}$ and $m=1.66$, considering the ideal solar cell, are shown in Figure 6.

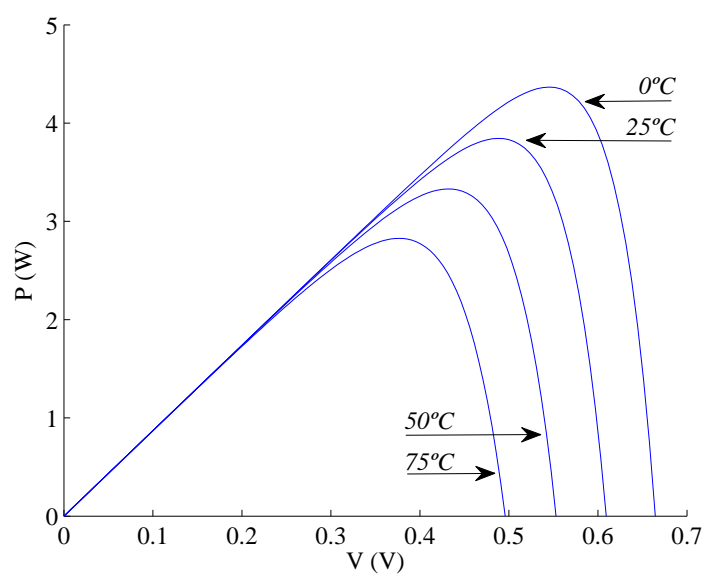

Fig. 6. $\mathrm{P}-\mathrm{V}$ characteristics for the temperature variation between 0 and $75^{\circ} \mathrm{C}$.

The I-V characteristics for various conditions of solar radiation and $m=1.66$, considering the solar cell with series resistance, are shown in Figure 7.

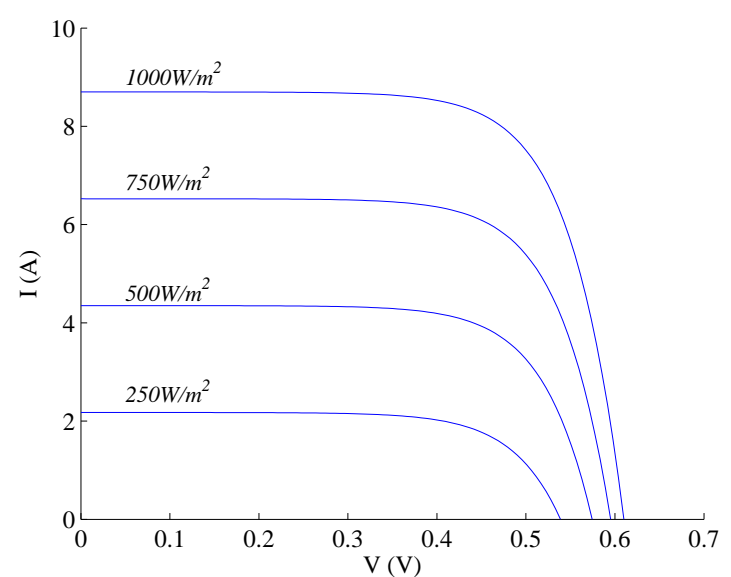

Fig. 7. I-V characteristics for various conditions of solar radiation (considering series resistance).

The I-V characteristics for a diode ideality factor variation between 1 and 2, considering the solar cell with series resistance of $R_{s}=20 \mathrm{~m} \Omega$, are shown in Figure 8 . 


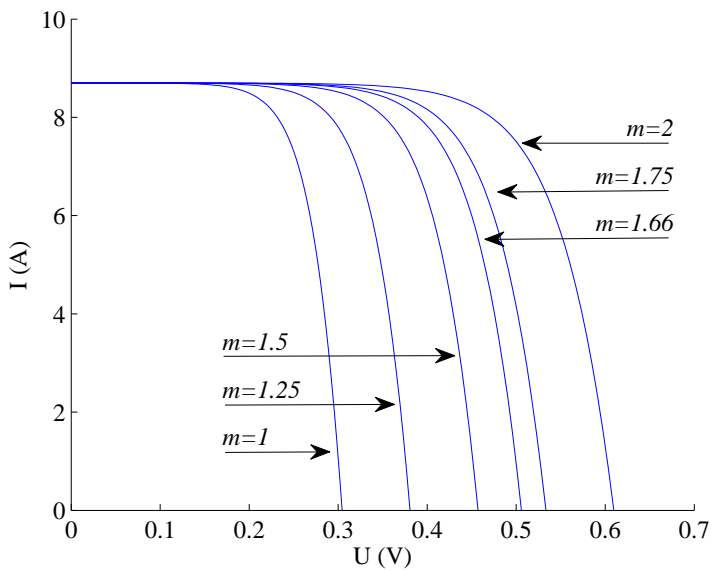

Fig. 8. I-V characteristics for a diode ideality variation between 1 and 2 (considering series resistance).

The I-V characteristic for a temperature variation between 0 and $75^{\circ} \mathrm{C}$ and $m=1.66$, considering the solar cell with series resistance of $R_{s}=20 \mathrm{~m} \Omega$, are shown in Figure 9.

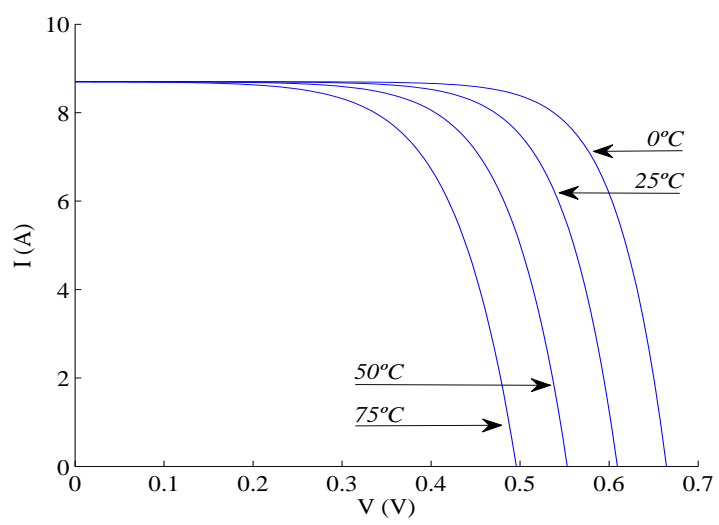

Fig. 9. I-V characteristics for the temperature variation between 0 and $75^{\circ} \mathrm{C}$ (considering series resistance).

The P-V characteristics for the temperature variation between 0 and $75^{\circ} \mathrm{C}$ and $m=1.66$, considering the solar cell with series resistance of $R_{s}=20 \mathrm{~m} \Omega$, are shown in Figure 10. The P-V characteristics for $R_{s}=20 \mathrm{~m} \Omega$ are shown in Figure 11.

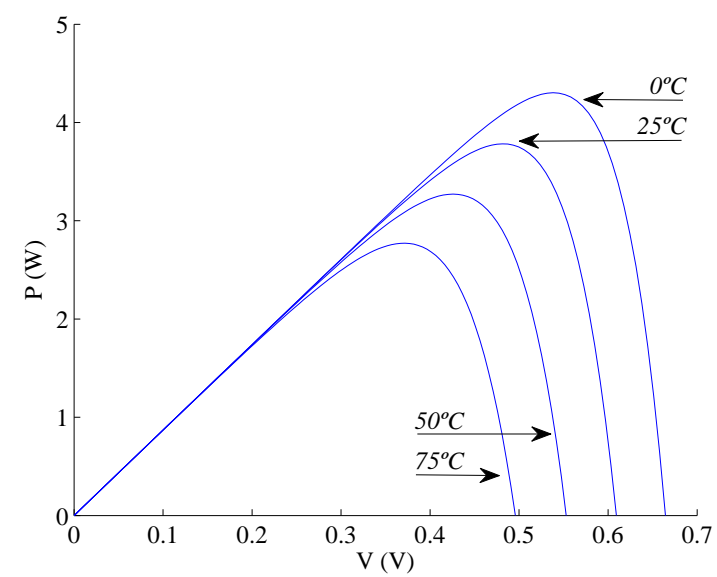

Fig. 10. P-V characteristics for the temperature variation between 0 and $75^{\circ} \mathrm{C}$ (considering series resistance).

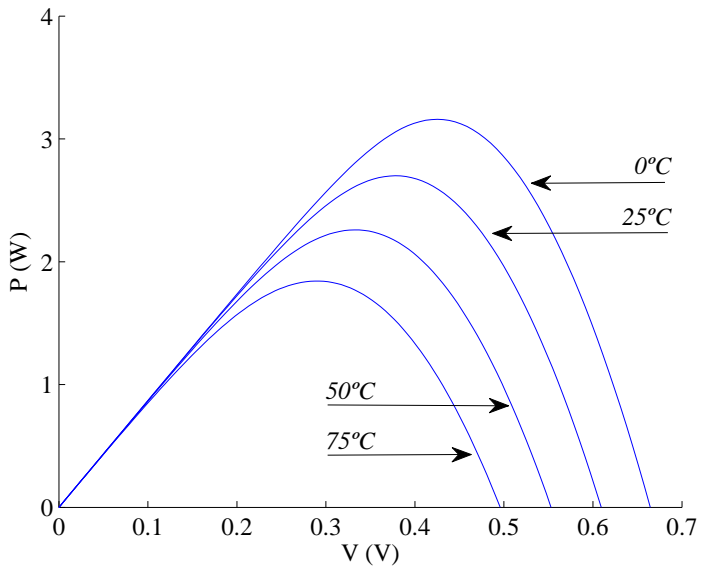

Fig. 11. P-V characteristics for $R_{s}=20 \mathrm{~m} \Omega$.

The P-V characteristics for the $R_{s}$ variation between 0 and $20 \mathrm{~m} \Omega$ are shown in Figure 12.

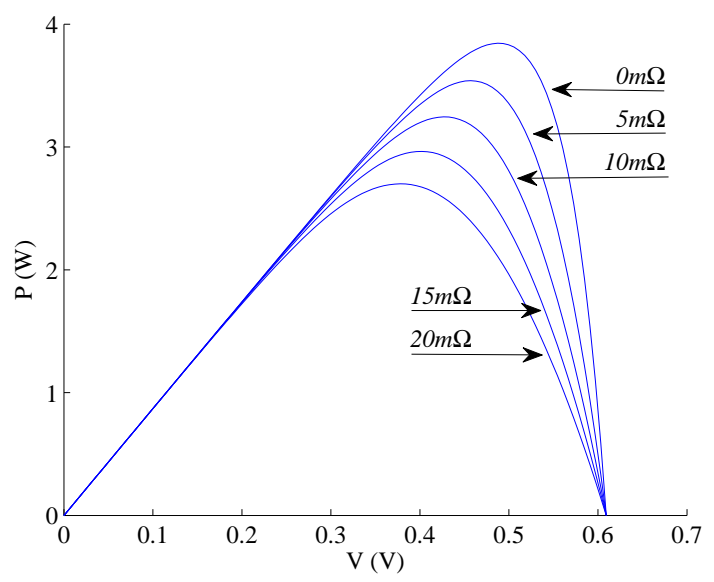

Fig. 12. P-V characteristics for the $R_{s}$ variation.

With the change of the temperature, the solar radiation, and the diode ideality factor, the I-V and P-V will change accordingly.

\section{Conclusion}

The behaviour of ideal solar cell model and the behaviour of the solar cell with series resistance model are studied in this paper. Included effects are: temperature dependence, solar radiation change, diode ideality factor and series resistance influence. The solar cell with series resistance model offers a more realistic behaviour for the photovoltaic systems. Particularly, this model is to be considered in panels with series cells, because the series resistance is proportional to the number of solar cells in the panel.

\section{References}

[1] F. Spertino and J. S. Akilimali, "Are manufacturing I-V mismatch and reverse currents key factors in large photovoltaic arrays?", IEEE Transactions on Industrial Electronics, Vol. 56, No. 11, pp. 4520-4531, Nov. 2009. 
[2] M. Laranja, "Portuguese National Strategy ENE 2020". Available: http://www.ccr-norte.pt/norte2020/laranja.pdf

[3] M. G. Villalva, J. R. Gazoli, and E. R. Filho, "Comprehensive approach to modeling and simulation of photovoltaic arrays", IEEE Transactions on Power Electronics, Vol. 24, No. 5, pp. 1198-1208, May 2009.

[4] A. S. Sedra and K. C. Smith, Microelectronic Circuits. London, U.K.: Oxford Univ. Press, 2006.

[5] M.A. Eltawil, Z. Zhao, "Grid-connected photovoltaic power systems: Technical and potential problems-A review", Renewable and Sustainable Energy Reviews, Vol. 14, No. 1, pp. 112-129, Jan. 2010.
[6] "Photovoltaic systems technology," Universitat Kassel, Kassel, Germany, 2003.

[7] G.R. Walker, "Evaluating MPPT topologies using a Matlab PV model", Journal of Electrical \& Electronics Engineering, Vol. 21, No. 1, pp. 49-56, 2001.

[8] J. Yuncong, J.A.A. Qahouq, and I. Batarseh, "Improved solar PV cell Matlab simulation model and comparison", in: Proc. 2010 IEEE International Symposium on Circuits and Systems - ISCAS'10, Tuscalosa, Alabama, USA, 2010. 